


\title{
Studi eksperimen kinerja turbin vortex berbasis gravitasi dengan sudu backward dan forward
}

\section{Experimental study on the performance of gravitational water vortex turbine with backward and forward blade}

\section{D.S. Pamuji, F. Akbar, A.N. Rohman, D. Sugati}

Program Studi Teknik Mesin, Fakultas Teknologi Industri, Institut Teknologi Nasional Yogyakarta, Jl. Babarsari, Depok, Sleman, D.I. Yogyakarta 55281, Indonesia. HP. 0895359004107

*E-mail: didit@itny.ac.id

Article History:

Received 26 January 2021

Accepted 19 February 2021

Available online 01 April 2021

Keywords:

Backward blade

Forward blade

Micro-hydro

Vortex turbine

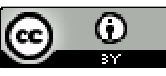

Nowadays, the use of hydro energy in Indonesia is still focused on large-scale hydropower development which has negative effects on the environment such as changes in the natural flow of rivers, disruption of the population of aquatic biota that live in these watersheds and has the risk of potential disasters if the dam fails. In fact, the energy potential from the mini-micro hydro source is $19,835 \mathrm{MW}$, but its utilization is still very low around 100 $M W$. Therefore, the extraction of water flow energy in the form of rivers and irrigation channels with very low head altitude differences is considered important and urgent so that a gravity vortex turbine-based mini / micro hydro research is proposed. Specifically, this study aims to analyze the performance of the vortex turbine with backward and forward blades in a conical basin through laboratory experimental devices. Experiments were carried out on a fluid flow rate of 120 liters per minute (Ipm) and $100 \mathrm{lpm}$ by loading using a prony brake dynamometer in order to obtain torque performance data on variations in turbine blade rotational speed. In this experiment, the results showed that the performance of the backward blade turbine was superior with its optimal efficiency reaching $36.7 \%$ at a discharge of $120 \mathrm{lpm}$ and a rotating speed of $80 \mathrm{rpm}$ than the forward blade which at a discharge of $120 \mathrm{lpm}$ and a rotating speed of $80 \mathrm{rpm}$ was only able to achieve its highest efficiency at $33.19 \%$.

\section{INTRODUCTION}

Hydro energy is one of the cheapest, most widely available and most productive forms of renewable energy, among other renewable sources of energy (Hanafi and Riman, 2015). In Indonesia, the use of water energy potential is still concentrated on a large scale at $19.1 \%$, while the potential for mini-microhydro is not yet developed at only $0.013 \%$ (Yudiarto et al, 2018). The extraction of mechanical 
Dinamika Teknik Mesin. Pamuji dkk.: Experimental study on the performance of gravitational water vortex turbine with backward and forward blade

energy from water flows in the form of rivers and irrigation canals with a very low difference in height (very low head) is considered to be one of the solutions to meet the needs of electricity in remote areas, which are still limited by the economic problems of building new electricity grids, low electricity demand and loading factors (Erinofiardi et al., 2017), and reduce the negative impacts of dam construction (Talukdar et al., 2018).

The gravitational water vortex is one form of mini/microhydro power plant that is being designed for the use of water energy with a very low head. Research on free vortex turbines is capable of producing a maximum mechanical efficiency of $35.92 \%$, which is far higher than traditional water wheels, which only produce a maximum mechanical efficiency of $13.69 \%$ (Sritram and Suntivarakorn, 2017; Nishi and Inagaki, 2017). Previous research has shown that there are many factors that affect the efficiency of the free water vortex turbine, such as vortex pool design, configuration of the turbine and material, and changes in flow rate parameters (Power et al., 2015).

Gravitational Water Vortex Power Plant (GWVPP) is a type of renewable energy technology that uses water sources and is classified as mini-micro-hydro because the recorded generation of electricity does not exceed $100 \mathrm{~kW}$ (Yaakob et al., 2014). In this plant, the water is initially flowed into an artificial channel, and then flows tangentially into a circular basin to create a natural vortex or a free vortex. This power plant needs only a low head $(0.5-1 \mathrm{~m})$ so that the energy conversion process is not based on variations in pressure, but energy due to changes in the dynamic force produced by the vortex is transferred into a turbine mechanic shaft.

In order to increase turbine efficiency, there is still a lot of potential for further analysis in terms of design and configuration. Literature review of the GWVPP variables can be divided into three variable groups, namely basin configuration, inlet basin and outlet orifice configuration, and turbine configuration. Research conducted (Dhakal et al., 2015) shows using computational fluid dynamics that the use of the conical basin type is capable for producing higher efficiency than the cylinder basin. The research was then continued with an experimental study using a conical basin, with a discharge of $0.01 \mathrm{~m}^{3} / \mathrm{s}$ and a height of $0.85 \mathrm{~m}$, indicating that the runner position would produce an optimal efficiency of $36.85 \%$ when placed in a position of $65-75 \%$ of the total fall height, measured from above the basin.

In terms of turbine configuration, research on suitable turbine characteristics through optimization of shape, blade profile, number and size still has a great opportunity to be further developed. The results of research Power et al., (2015) which states that the efficiency of the generator increases with the increase in the number of turbines (from 2 to 4 ) is in contrast to the findings that the efficiency of the generator decreases when the number of turbine blades is increased (Dhakal et al., 2014) and the size of the turbines has a large effect on the efficiency of the generator. Furthermore, from the material side of the turbine, aluminum material produces higher power efficiency than turbines that use iron materials (Sritram et al., 2015).

The function of the water turbine in general is as a tool to extract flow energy so that a pressure drop occurs after the flow out of the turbine through the momentum transfer mechanism from the vortex flow to the turbine blade surface (Cengel and Cimbala, 2014). Turbine designs involving free water surfaces are quite complicated and the flow patterns formed for the different turbine types have not been thoroughly clarified. The use of a turbine similar to a radial flow type cross flow with the shape of 20 backward blades was used by Nishi and Inagaki (2017) in the cylindrical basin and resulted in an efficiency of up to $35.4 \%$ both in CFD simulations and experiments. The CFD results also show how the flow field characteristics are formed around the turbine blades. The shape of the radial flow type turbine blades in the vortex for generation purposes has not been widely studied, therefore, based on the background and review of previous literature, this research will focus on examining more deeply the different types of backward and forward blades in a gravity vortex turbine to compare the performance of torque, power, and efficiency through laboratory experimental studies.

\section{RESEARCH METHOD}

\subsection{Basin and turbine specification}

The object of research initially refers to the turbine type model and flow parameters carried out by Nishi and Inagaki (2017), then the basin is modified to a conical shape as shown in Figure 1. The turbine type model used refers to the design parameters of the curved backward blade with the characteristics shown in Figure 2. and a description of the dimensions in Table 1. Furthermore, the type of curved backward blade is varied to be in the form of a curved forward blade which will be compared its performance, the design is as shown in Figure 3. 
Dinamika Teknik Mesin. Pamuji dkk.: Experimental study on the performance of gravitational water vortex turbine with backward and forward blade
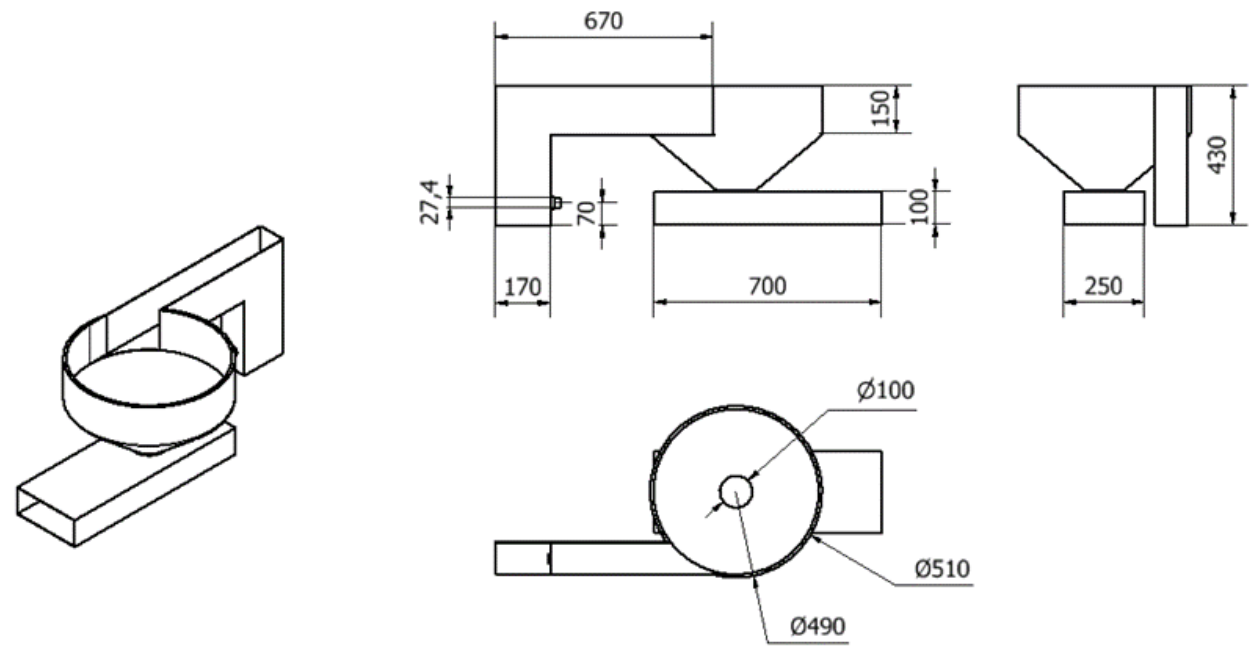

Figure 1. Conical basin model in this study, in $\mathrm{mm}$
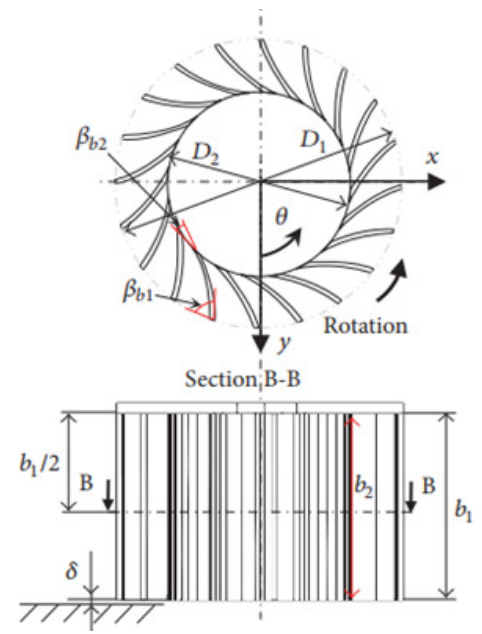

Figure 2. Curved backward blade design parameters that are used as a reference (Nishi and Inagaki, 2017)

Tabel 1. Blade design parameters (Nishi and Inagaki, 2017)

\begin{tabular}{ll}
\hline Parameter & \\
\hline Outer diameter, $D_{1}$ & $14 \mathrm{~cm}$ \\
Inner diameter, $D_{2}$ & $9,1 \mathrm{~cm}$ \\
Inlet width, $b_{1}$ & $0,91 \mathrm{~cm}$ \\
Outlet width, $b_{2}$ & $0,91 \mathrm{~cm}$ \\
Inlet angle, $\beta_{b 1}$ & $71,9^{\circ}$ \\
Outlet angle, $\beta_{b 2}$ & $19,0^{\circ}$ \\
Number of blade, $Z$ & 20 \\
\hline
\end{tabular}



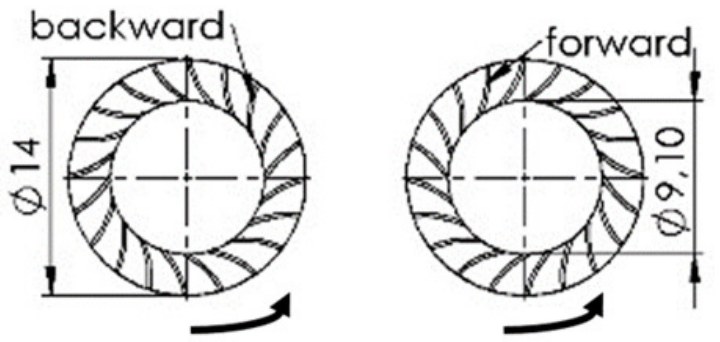

Figure 3. Backward and forward blade design

\subsection{Experimental apparatus}

The design of the experimental equipment used in this study can be seen in Figure 4. Water from inside the reserve tank is pumped and then adjusted using a valve to obtain a flow rate that can be read on the rotameter / flowmeter. In this study, differences in performance will be observed for both backward and forward blade types with a discharge of 100 liter per minute $(\mathrm{Ipm})$ or about $0.00167 \mathrm{~m}^{3} / \mathrm{s}$ and 120 liter per minute (lpm) or about $0.00200 \mathrm{~m}^{3} / \mathrm{s}$. The piping system uses a diameter of 1 ", water from the pipe is first collected at the inlet tank with a width of $10 \mathrm{~cm}$ to produce a certain level before entering the basin with a diameter of $49 \mathrm{~cm}$. The vortex flow that is formed then rotates the runner and its performance is observed using a DIY prony brake unit which provides information in the form of shaft rotation speed data, force data read on the load cell, and torque conversion after multiplying by $4.5 \mathrm{~cm}$ of torque arm.

The experimental test scheme for the gravitational water vortex turbine is shown in Figure 5 . The designs of the backward and forward blade turbines are printed using a 3d printing machine with PLA material. Measurement of turbine shaft torque performance was carried out using a DIY prony brake dynamometer using an arduino micrcontroller. The load on the shaft is regulated by tightening / loosening the bolt on the brake ring, resulting in a certain shaft rotational speed read by the photointerupter sensor and the shaft rotational load mass read by the $1 \mathrm{~kg}$ load cell Model T124GA, which is then programmed into output data in the form of turbine shaft torque.

The mechanical power of the turbine shaft is calculated using Equation 1. The effective head $\mathrm{H}$ is defined by Equation 2, as described in Figure 6.

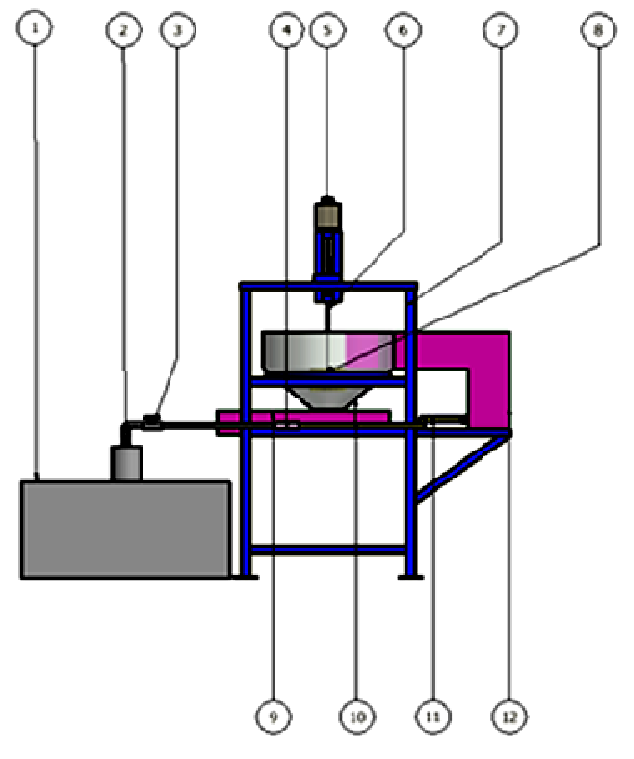

Note:



1. Reserve tank

2. Pump

3. Valve

4. Flowmeter

5. Prony brake unit

6. Shaft

7. Frame

8. Runner

9. Outlet channel

10. Basin

11. Pipe $1^{*}$

12. Inlet tank

13. Disk for RPM sensor

14. Photo interrupter

15. Torque arm

16. Load cell

Figure 4. Design of experimental apparatus 
Dinamika Teknik Mesin. Pamuji dkk.: Experimental study on the performance of gravitational water vortex turbine with backward and forward blade

$P=\frac{2 \pi n T}{60}$

where $P$ is mechanical power of the turbine shaft (watt), $n$ is rotational speed of the shaft (rpm), $T$ is torque of the shaft $(\mathrm{Nm})$.

$H=h^{r}+h_{1}+\frac{v_{1}^{2}}{2 g}-h_{2}-\frac{v_{2}^{2}}{2 g}$

where $\mathrm{H}$ is the effective head $(\mathrm{m})$ for mechanical efficiency calculation as described in Figure 6.

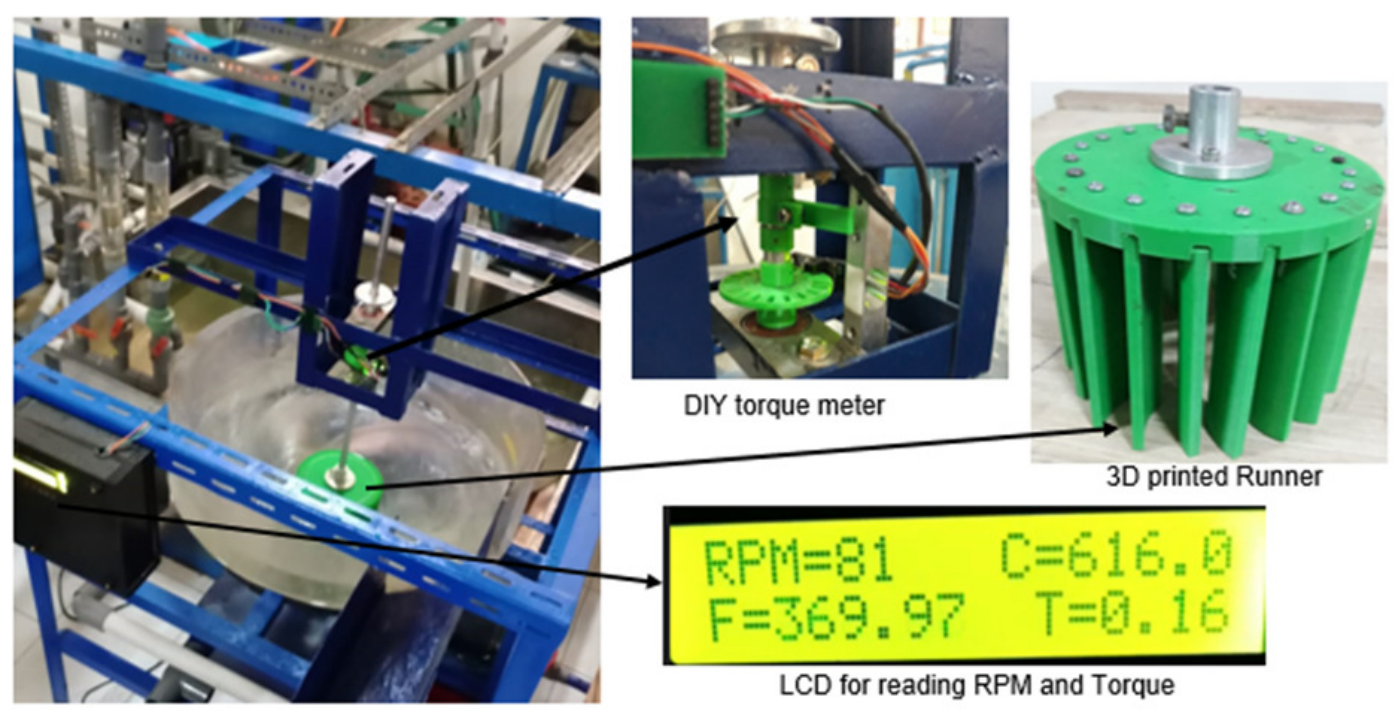

Figure 5. Experimental apparatus

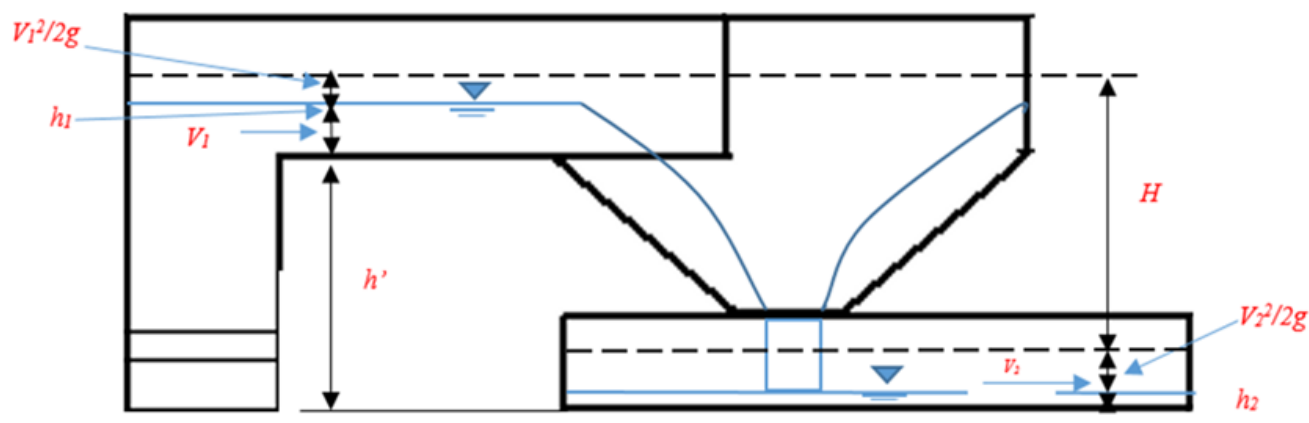

Figure 6. Effective head $\mathrm{H}$ evaluation

The upstream velocity to the basin $v_{1}(\mathrm{~m} / \mathrm{s})$, and the downstream velocity from the basin $v_{2}(\mathrm{~m} / \mathrm{s})$ could be calculated by using Equation 3 and Equation 4, as follow,

$$
\begin{gathered}
v_{1}=\frac{Q}{B_{1} h} \\
v_{2}-\frac{Q}{B_{2} h_{2}}
\end{gathered}
$$


Dinamika Teknik Mesin. Pamuji dkk.: Experimental study on the performance of gravitational water vortex turbine with backward and forward blade

where $B_{1}$ is the upstream channel width $(\mathrm{m})$ of $0.1 \mathrm{~m}, B_{2}$ is the downstream channel width $(\mathrm{m})$ of $0.25 \mathrm{~m}$, and $Q$ is the water discharge $\left(\mathrm{m}^{3} / \mathrm{s}\right)$. Furthermore, the mechanical efficiency of the system was calculated using Equation 5.

$\eta=\frac{P}{\rho g Q H} \times 100 \%$

where $\rho$ is the density of water $\left(1000 \mathrm{~kg} / \mathrm{m}^{3}\right)$ and $\mathrm{g}$ is the gravitational accelaration $\left(9.81 \mathrm{~m} / \mathrm{s}^{2}\right)$.

\section{RESULTS AND DISCUSSION}

The comparison of the amount of torque and power generated by the curved backward and forward curved turbine blades with several variations of the rotational speed at the flow rate of $120 \mathrm{lpm}$ and 100 $\mathrm{lpm}$ is shown in Figure 7. Based on this graph, it is observed that at a discharge of $120 \mathrm{lpm}$, at all variations of the turbine rotation speed The value of the torque generated and the mechanical power generated by the turbine with the curved backward blade is almost the same as the forward blade arch, but at $100 \mathrm{lpm}$ the performance of the backward blade turbine is higher than the forward blade.

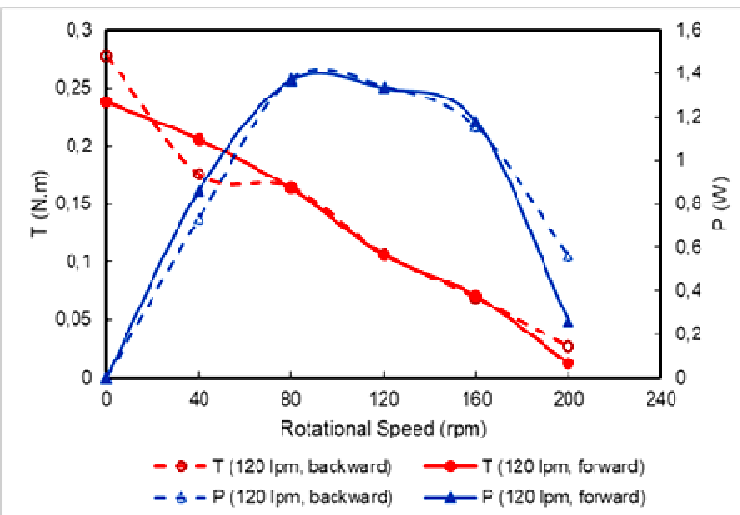

(a) Torque and turbine power at $120 \mathrm{lpm}$

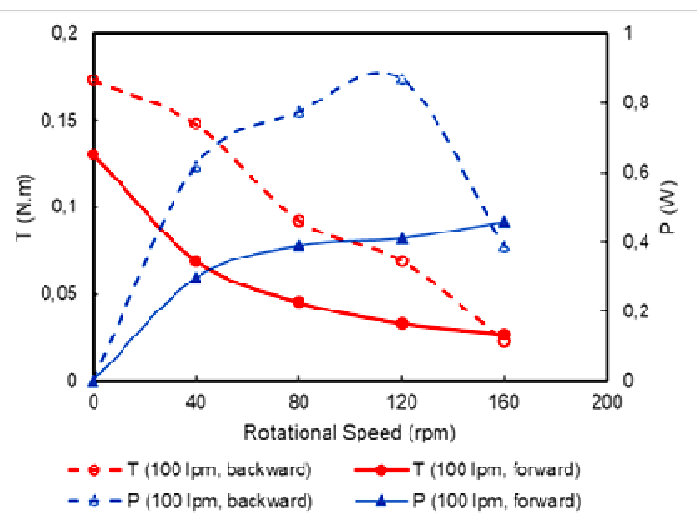

(b) Torque and turbine power at $100 \mathrm{lpm}$

Figure 7. Turbine performance comparison

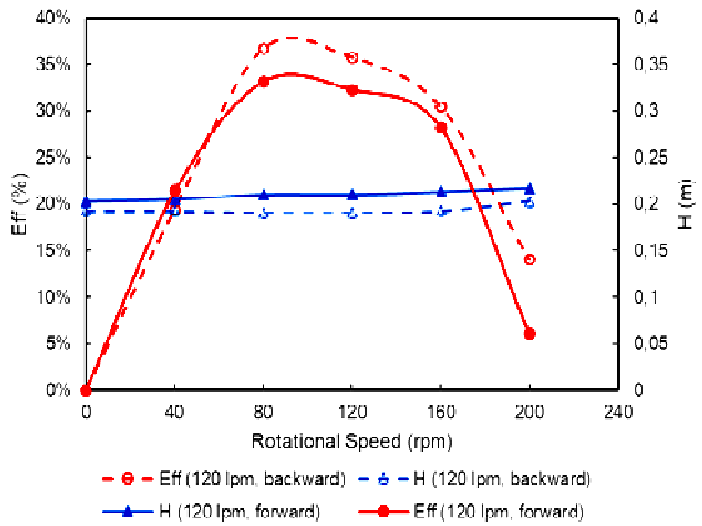

(a)

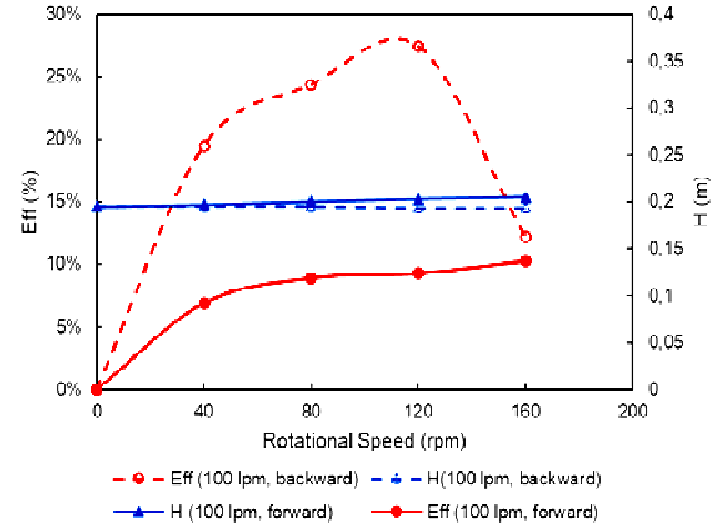

(b)

Figure 8. Turbine performance comparison: (a) Efficiency and effective head at $120 \mathrm{lpm}$, (b) Efficiency and effective head at $100 \mathrm{lpm}$

Based on the torque to rpm data, it can be seen that the torque decreases with increasing rpm. This happens because of the reduced reaction force due to the reduced speed difference between the 
Dinamika Teknik Mesin. Pamuji dkk.: Experimental study on the performance of gravitational water vortex turbine with backward and forward blade

water rotation speed and the turbine rotation. Referring to Equation (1), the optimal mechanical power generated occurs at a rotational speed of about $80 \mathrm{rpm}$, both backward and forward curved turbine blades reach 1.4 watt at a discharge of $120 \mathrm{lpm}$. However, at a discharge of $100 \mathrm{lpm}$, it was observed that the optimal power was achieved by the backward blade turbine at a rotational speed of 120 rpm, while the power generated by the forward blade turbine was only about 0.4 watt at $120 \mathrm{rpm}$.

When the rotational speed increases, the torque value generated by the shaft decreases, and the effective head $\mathrm{H}$ tends to increase slightly. This is because when the rotational speed increases, the area around the side of the turbine tends to be dominated by air, causing the water level on the upstream side $\mathrm{h}_{1}$ to tend to rise.

Based on (Marian, 2012) study, the rotational speed produced by the turbine is proportional to the vortex flow generated and the vortex height affects the efficiency of its power generation. Figure 8 shows the relationship between efficiency and effective head $\mathrm{H}$ on the turbine rotational speed. In accordance with the optimal power achieved in Figure 7 and the measurement of effective head $\mathrm{H}$, the highest efficiency of around $36.7 \%$ is also achieved by the backward blade turbine, while the forward blade has the highest efficiency of $33.19 \%$ at a rotating speed of $80 \mathrm{rpm}$ and a discharge of $120 \mathrm{lpm}$. Whereas at $100 \mathrm{lpm}$ discharge, the measurement results show the backward blade turbine can reach its highest efficiency of around $27.5 \%$, while the forward blade is only $12.4 \%$ at a rotating speed of $120 \mathrm{rpm}$.

\section{CONCLUSION}

Based on the experiments that have been carried out, the vortex flow that is formed in the basin is not a free vortex flow, but is influenced by the rotation of the turbine blades. Quantitatively, the performance of torque, power, and efficiency of turbines with backward blades are higher than the forward blades used in this study at almost all blade rotational speeds for both 120 lpm and 100 lpm flow rates. In the $120 \mathrm{lpm}$ discharge trial, both the backward and forward blade turbines produced almost the same torque and power values and reached an optimal power value of 1.4 watts at a rotating speed of 80 rpm, with a maximum efficiency calculated at 36.7\% and 33, 19\% for backward and forward blades, respectively. In the lower flow test, $100 \mathrm{lpm}$, it can be seen that the backward blade turbine performance is superior to that of the forward blade for all variations of rotational speed. This is predicted because the radial flow reaction turbine with the backward blade is more capable of extracting the vortex flow energy through the momentum transfer mechanism than the forward blade type.

\section{ACKNOWLEDGMENT}

The author would like to thank the Deputy for Strengthening Research and Development of the Ministry of Research and Technology / National Research and Innovation Agency for financing this research in the 2020 budget year.

\section{REFERENCE}

Cengel Y.A., Cimbala J.M., 2014, Fluid mechanics - fundamentals and applications, 3rd Edition McGrawHill Education, New York.

Dhakal S., Nakarmi S., Pun P., Thapa B.A., Bajracharya R.T., 2014, Development and testing of runner and conical basin for gravitational water vortex power plant. Journal of the Institute of Engineering, 10(1), 140-148.

Dhakal S., Timilsina A.B., Dhakal R., Fuyal D., Bajracharya T.R., Pandit H.P., Nakarmi A.M., 2015, Comparison of cylindrical and conical basins with optimum position of runner: Gravitational water vortex power plant, Renewable and Sustainable Energy Reviews, 48, 662-669.

Erinofiardi, Gokhale P., Date A., Akbarzadeh A., Bismantolo P., Suryono A.F., Nuramal A., 2017, A Review on Micro Hydropower in Indonesia, Energy Procedia, 110(December 2016), 316-321.

Hanafi J., Riman A., 2015, Life cycle assessment of a mini hydro power plant in Indonesia: A case study in Karai River, Procedia CIRP, 29, 444-449.

Nishi Y., Inagaki T., 2017, Performance and flow field of a gravitation vortex type water turbine, International Journal of Rotating Machinery, 2017.

Power C., McNabola A., Coughlan P., 2015, A Parametric experimental investigation of the operating conditions of gravitational vortex hydropower (GVHP), Journal of Clean Energy Technologies, 4(2), $112-119$.

Sritram P., Treedet W., Suntivarakorn R., 2015, Effect of turbine materials on power generation efficiency from free water vortex hydro power plant, IOP Conference Series: Materials Science and Engineering, 103(1).

Sritram P., Suntivarakorn R., 2017, Comparative study of small hydropower turbine efficiency at low head water, Energy Procedia, 138, 646-650. 
Dinamika Teknik Mesin. Pamuji dkk.: Experimental study on the performance of gravitational water vortex turbine with backward and forward blade

Talukdar P.K., Kulkarni V., Saha U.K., 2018, Field-testing of model helical-bladed hydrokinetic turbines for small-scale power generation, Renewable Energy, 127, 158-167.

Yaakob O.B., Ahmed Y.M., Elbatran A.H., Shabara H.M., 2014, A review on micro hydro gravitational vortex power and turbine systems, Jurnal Teknologi (Sciences and Engineering), 69(7), 1-7.

Yudiarto A., Sugiyono A., Wahid L., Adiarso, 2018, Indonesia energy outlook 2018, Development. Sekretariat Jenderal Dewan Energi Nasional: Jakarta. 